\title{
Age, Maturity and Gender, and the Propensity towards Surface and Deep Learning Approaches amongst University Students
}

\author{
Warren Lake, William Boyd \\ School of Environment, Science \& Engineering, Southern Cross University, Lismore, Australia \\ Email: warren.lake@scu.edu.au,william.boyd@scu.edu.au
}

Received 26 November 2015; accepted 22 December 2015; published 25 December 2015

Copyright (C) 2015 by authors and Scientific Research Publishing Inc.

This work is licensed under the Creative Commons Attribution International License (CC BY).

http://creativecommons.org/licenses/by/4.0/

(c) (i) Open Access

\section{Abstract}

The approach that a student takes towards their study has a substantial impact on the quality of their learning and academic success-a deep rather than surface approach more likely to be associated with academic success. Using the validated study processes questionnaire developed by Biggs et al. (2001), this study surveys over $\mathbf{5 0 0}$ undergraduate students across one university to examine patterns of learning approaches against age, maturity and gender. Analysis indicates that age is important in terms of the tendency towards adopting a deep or surface learning approach; mature age students are more likely to adopt a deep learning approach and less likely to adopt a surface approach. There are no significant differences in deep or surface approach scores between genders. However, in relation to maturity, both mature age males and females score a statistically higher score on deep motive compared to usual age females. However, this is not the case for usual age males, with no significant difference found. This same pattern also occurred for the deep strategy subscale component. Mature males and females, as well being more motivated to adopt deep learning approaches, undertake strategies that are more likely to lead to a higher scale scores compared to usual age females but not usual age males.

\section{Keywords}

Student Approaches to Learning (SAL), Study Processes Questionnaire (SPQ), R-SPQ-2F, Mature Age Student, Gender, Discipline, Age

\section{Introduction}

Maintaining high academic standards in today's larger and more diversified university classes presents major

How to cite this paper: Lake, W., \& Boyd, W. (2015). Age, Maturity and Gender, and the Propensity towards Surface and Deep Learning Approaches amongst University Students. Creative Education, 6, 2361-2371. 
challenges for many teachers (Biggs, 1999; James, Krause, \& Jennings, 2010). The natural abilities of students to adapt to study at university in contemporary times are thought to be greatly influenced by the both in the approach a student takes towards their learning and the enabling conditions set by teachers, rather than simply a student's fixed characteristics (Biggs, Kember, \& Leung, 2001; Holley \& Oliver, 2010; Sherry, Thomas, \& Chui, 2010). Although fixed characteristics are still considered to be an important influence forming part of an interactive complex system (Jiao, 2005); both teacher and student are, therefore, responsible for producing positive learning outcomes. This poses an important question as to whether the university experience is primarily responsible for pushing some students towards a superficial surface type learning approach or whether a student's age or motivational disposition are more important factors. Many of these issues in higher education research have been studied since the early 1970s, in different research traditions, including, for example, the study of "learning styles" and "learning approaches". Learning approach studies are first popularised by Marton and Säljö in the mid-1980s (Case \& Marshall, 2004; Marton \& Säljö, 1984), which lead to the development of the Approaches to Study Inventory (ASI) (Watkins \& Hattie, 1985), and later Biggs (1987a) in the form of the Study Processes Questionnaire (SPQ). Although some terminology between these lines of study ("learning styles" and "learning approaches”) appears to be used somewhat interchangeable, the study reported here focuses on what is frequently referred to as Student Approaches to Learning.

In self-reporting surveys such as the revised two-factor Study Process Questionnaire (R-SPQ-2F) used in this survey, deep approach/engagement is regularly associated with more successful performance, while reliance on shallow strategies is generally considered insufficient for academic success (Greene, 2015). At this point, it is important to point out that although newer models such as the "Learning patterns model", which also originates out of the Student Approaches to Learning tradition, consider additional learning dimensions, and the revised SPQ still provides a different viewpoint with regards to context-specificity and changeability of student learning approaches (Vanthournount, Donche, Gijbels, \& Petegem, 2014). Importantly, Vanthournount et al. (2014) point out that these two models "... do not necessarily have to collide" due to the more general nature of the Learning patterns model as opposed to the earlier SAL model and its variants, which primarily situate “... at the level of the course or the learning environment” (p.18).

Although there is often considered to be many weaknesses regarding studies that focus on specific learning dimensions/traditions/tools (Cofeld, Moseley, Hall, \& Ecclestone, 2004), there are obvious similarities in the construct definitions and in the scale development process (Greene, 2015). Studies that use tools that have been validated to cover specific dimensions, are clearly important for adding to the pool of knowledge regarding student learning; given the complex nature of learning, it is fair to make the pragmatic claim that it is unlikely to be addressed using any one particular model. What is clear from research is that the teaching and learning process has an inherent complex nature, with many issues still necessary for researchers to investigate (Freeth \& Reeves, 2004; Opfer \& Pedder, 2011; Regan, 1996; Zeegers, 2001). An additional point of relevance and argument for continued research on tools such as the R-SPQ-2F is the extreme length of newer tools, which attempt to capture more dimensions (i.e. Inventory of Learning Styles (ILS) $=120$ Questions), compared with more diagnostic tools such as the R-SPQ-2F (20 questions) that are more suitable for implementation by practitioners. For these reasons, including its continued use in subsequent studies (i.e. Pyke, Porter-Dabrowski, \& Williamson, 2014; Socha \& Sigler, 2014), it remains important to investigate and add to the body of knowledge regarding the validity and usefulness of the R-SPQ-2F. Additionally, models based on learning approaches and strategies in teaching-learning process are often considered to be a useful guide for departments and institutions wanting to engage in a process of critical reflection on current practice (Cofeld, Moseley, Hall, \& Ecclestone, 2004).

Early research into learning approaches indicates that the approach a student takes towards the study has a substantial impact on the quality of their learning and academic success (Clayton, Blumberg, \& Auld, 2010); a deep rather than surface approach is more likely to be associated with academic success (Biggs, 1987b; Diseth, 2003; Diseth \& Kobbeltvedt, 2010; Entwistle, Tait, \& McCune, 2000; Regan, 1996). Additionally, Biggs (1991) indicates that a student's interest in learning is often as important as the structure, delivery and assessment of content, and is important in whether, especially, a surface approach is adopted. Importantly, the tendency towards choice of learning approach appears to be age-related (Biggs, 1987b; Zeegers, 2001; Baeten, Kyndt, Struyven, \& Dochy, 2010). Given that many students in higher education are in the late adolescent/young adult age range, a period of which learning styles are potentially still being developed by the student (Gremli, 2003), this may be unsurprising. However, the higher education sector is experiencing a significant growth in older adult students (Ross-Gordon, 2011), and therefore, the issue of age-related factors, and their potential implica- 
tions in terms of student performance and educational outcomes, is becoming increasingly significant. While the influence of age has been acknowledged by many researchers, the causal factors associated with age in relation to adoption of learning approach are less clear (Diseth, Pallesen, Brunborg, \& Larsen, 2010). Toohey (1999) further points out that factors such as time-stress, rewards for low-level outcomes, and lack of choice of subjects in the classroom/departmental climate can all encourage a surface approach to learning, while Diseth et al. (2010) identify a wide range of predicating factors. Zeegers (2001) indicates that older students may be more willing or able to commit to the use of elaborate learning strategies, which, by their very nature, require greater effort. Harper and Kember (1986) suggest that the learning characteristics of older students can be accredited to three factors: motivational factors, the impact of secondary education, and the role of life experiences. Studies using various tools, such as the Study Processes Questionnaire and Approaches to Study Inventory (Watkins \& Hattie, 1985), have used gender as a differentiating variable, but have not conclusively established significant differences between male and female approaches to learning (Regan, 1996). This study addresses these issues, examining, first, patterns of learning approach in a large university student cohort, and examining relationships between age, gender, and scale scores obtained using the revised two-factor study process questionnaire (R-SPQ$2 \mathrm{~F})$. The aim is to determine if age and gender effects are prevalent in the university population, and to determine if student maturity is a factor that can be leveraged by researchers.

\section{Methods}

This study adopted Biggs et al.'s (2001) most recent version of his study processes questionnaire (R-SPQ-2F). The 20-question self-reporting questionnaire uses a Likert scale format to help assess students in terms of their approaches to learning. It does this through the identification of scores regarding motives and strategies, which are accumulated to give a scale score on each scale and subscale (Table 1). The questionnaire provides scores on Deep Approach (five questions related to deep strategies and five questions related to deep motives) and scores on Surface Approach (five questions related to surface strategies and five questions related to surface motives) (for a full list of these questions and operational explanations, see Biggs et al., 2001). Biggs' current version gives a researcher a clear and simple tool to provide overall scores on deep and surface learning, as well as clearly identifying motive and strategy sub-scales (Biggs et al., 2001).

The Biggs et al.'s 2001 (2001) study processes questionnaire formed the basis of an online survey, using the Qualtrics ${ }^{1}$ online survey tool, which targeted all Southern Cross University (SCU) students. SCU is a public university in Australia, delivering mostly three-year undergraduate degrees, postgraduate coursework and research degrees. The survey consisted of the twenty original questions from Biggs' survey plus additional demographic questions, such as age, and gender. The University's Human Research Ethics Committee approved the survey on 16 August 2013 (Approval Number ECN-13-214). An email alerting students to the survey was sent to all students currently enrolled at the University on Tuesday 08/27/13, with a follow up emails on the Friday 08/30/13, and Wednesday 09/04/13. The most popular time to complete the survey was 9:00 am followed closely by 10:00 am and 5:00 pm; the emails to encourage participation were sent out for the first two emails at approximately 9:00 am and the final email just prior to 5:00pm. The number of full or partially completed survey submissions was 560 out of a population of 11,881 students (population data provided by X University Student Administration).

Analysis involved comparisons of age-related factors, using a MANOVA with the two SPQ main-scales as the dependent variables, and age classification, gender classification, as the independent factors. The final step required that the data were partitioned into subscalesof motivation and strategy indicators, and these subscales-deep motive, deep strategy, surface motive, and surface strategy — were examined using a MANOVA to determine age and gender and cohort patterns.

\section{Results}

Of the 560 survey completions, 504 students fully completed the survey, and therefore were used in the analysis. Students did not complete every question either because they chose not to do so, or did not have critical information. There were more females (74\%) responding to the survey than males (26\%). This gender ratio reflects

\footnotetext{
${ }^{1}$ The survey, data input and output for this paper was generated using Qualtrics software, version 53607 of the Qualtrics Research Suite. Copyright (C) (2013) Qualtrics. Qualtrics and all other Qualtrics product or service names are registered trademarks or trademarks of Qualtrics, Provo, UT, USA. http://www.qualtrics.com
} 
data provided by the student administration department of the university. Of the students whom took the survey, more than $70 \%$ considered they were mature-aged. These figures are typical of the university's demographics, with recent studies (Markopoulos, Chaseling, Petta, Lake, \& Boyd, 2015) from the same university citing a high ratio of predominately female students (80\%). Markopoulos et al. also report a median age 19 years old, $74 \%$ regional and remote, $64 \%$ first-in-family at university, 31\% low socioeconomic, $2 \%$ Indigenous Aboriginal or Torres Strait Islander background and 1\% Non-English Speaking Background. Student age groups were distributed across an age range of 17 to 71 (Figure 1). In Biggs et al. (2001), Cronbach alpha values of 0.64 for deep approach and 0.73 for Surface Approach for the main scales were reported, levels that were considered internally consistent. In this study Cronbach alpha values of 0.86 for deep approach $(\mathrm{CFI}=0.94)$ and 0.81 for surface approach (CFI $=0.92)$ were considered highly satisfactory (CFI = Confirmatory factor analysis). All the bar graphs in this paper show mean values with error bars of \pm 1 S.E. Mature-age students and usual-age students are reported categories; usual-age students refer to students that have entered university directly after high school education, whereas mature-age students include all students over 23.

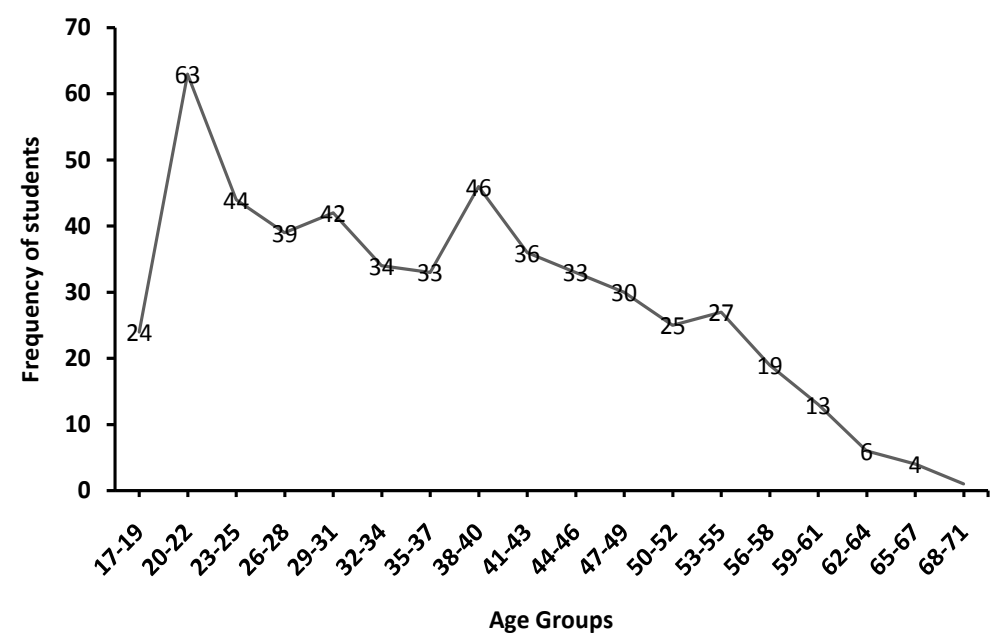

Figure 1. Age distribution of survey respondents.

Table 1. The psychometric properties key for the R-SPQ-2F being measured for each question relating to deep or surface approach and their subscales.

\begin{tabular}{|c|c|c|c|c|c|}
\hline Deep Approach (DA) & Surface Approach (SA) & $\begin{array}{l}\text { Deep Motive } \\
\text { (DM) }\end{array}$ & $\begin{array}{l}\text { Deep Strategy } \\
\text { (DS) }\end{array}$ & $\begin{array}{l}\text { Surface Motive } \\
\text { (SM) }\end{array}$ & $\begin{array}{c}\text { Surface Strategy } \\
\text { (SS) }\end{array}$ \\
\hline $\begin{array}{c}\text { Questions } 1+2+5+6+9+ \\
10+13+14+17+18\end{array}$ & $\begin{array}{l}\text { Questions } 3+4+7+8+11 \\
\quad+12+15+16+19+20\end{array}$ & $\begin{array}{c}1+5+9+ \\
13+17\end{array}$ & $\begin{array}{c}2+6+10+ \\
14+18\end{array}$ & $\begin{array}{c}3+7+11+ \\
15+19\end{array}$ & $\begin{array}{c}4+8+12+ \\
16+20\end{array}$ \\
\hline
\end{tabular}

\subsection{Main Scale Analysis-Gender and Age-Group}

A multivariate analysis (MANOVA) was used to examine the effects of age (mature-age and usual-age) and gender (male and female) on deep approach and surface approach main-scale scores. Assumptions of univariate normality was assessed with Shapiro-Wilk tests and boxplots, and could be assumed, no multivariate outliers were identified, no multicollinearity was found, and homogeneity of variance-covariance matrices were satisfied. Analysis of the dependent variables showed that there was a significant effect of the age variable (mature-age and usual-age) on the combined dependent variables (deep approach score and surface approach score), F (2, $514)=11.677, p=0.00$, partial $\eta 2=0.043$, but not Gender, $\mathrm{F}(2,514)=0.51, p=0.61$, partial $\eta 2=0.02$.

Analysis of dependent variables individually showed that at a Bonferroni adjusted alpha level of 0.25 , the age variable remained significant, for deep approach, $\mathrm{F}(2,514)=15.395, p=0.00$, partial $\eta 2=0.29$, and also significant for surface approach, $\mathrm{F}(2,514)=19.149, p=0.00$, partial $\eta 2=0.36$. Therefore, this indicates that mature-age students have a statistically higher deep approach score and statistically lower surface approach score compared to usual-age students (Figure 2). Gender was not statistically significant for either deep or surface approach, indicating the absence of any meaningful gender effects on scores (Figure 3). 


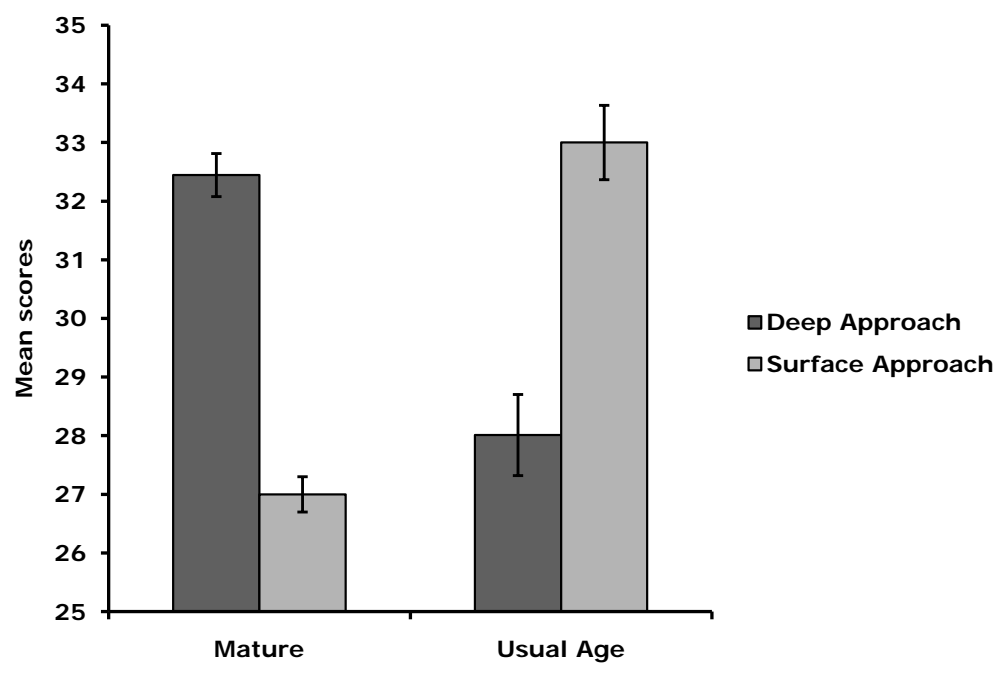

Figure 2. Mean ( \pm 1 standard error) deep and surface learning approach scores for mature and usual-age students.

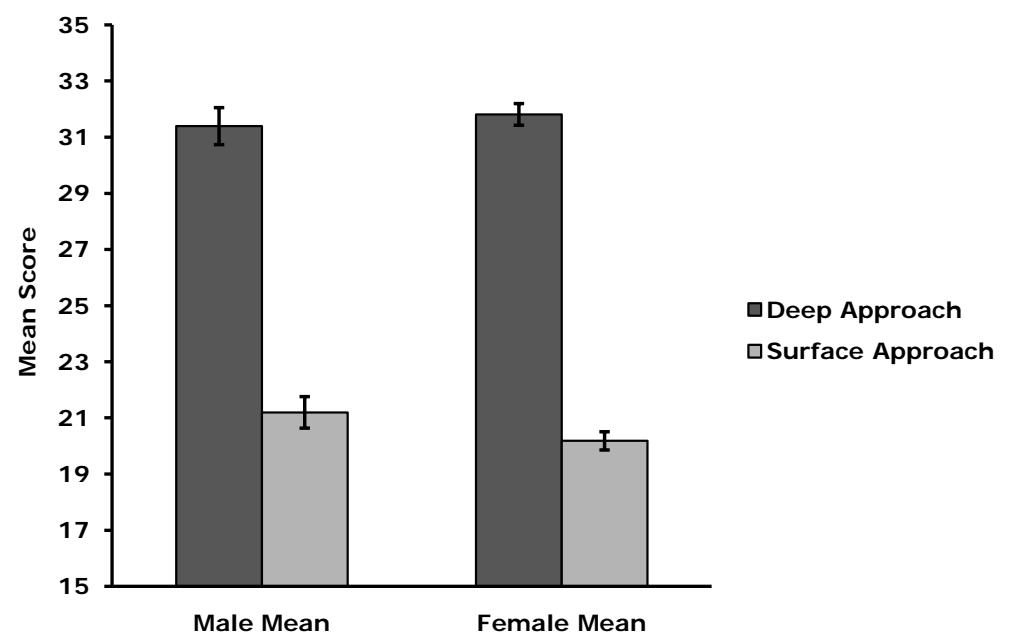

Figure 3. Mean ( \pm 1 standard error) score for deep and surface learning approaches, by gender.

However, when considering gender divided into four distinct cohorts for analysis-i.e. mature males, usualage males, mature-age females, usual-age females (Figure 4),

Analysis of the dependent variables showed that there was a significant effect of the age-gender variable (mature males, usual-age males, mature-age females, usual-age females) on the combined dependent variables (deep approach score and surface approach score), $\mathrm{F}(2,514)=8.817, p=0.00$, partial $\eta_{2}=0.49$.

Analysis of dependent variables individually showed that at a Bonferroni adjusted alpha level of 0.0125 , the age-gender variables remained significant, for deep approach, $\mathrm{F}(2,514)=11.514, p=0.00$, partial $\eta_{2}=0.63$, and also significant for surface approach, $\mathrm{F}(2,514)=15.221, p=0.00$, partial $\eta 2=0.82$.

Post hoc analysis of deep approach revealed that a significant difference occurs between mature-age females $(\mathrm{M}=32.74, \mathrm{SD}=3.88)$ and usual-age females $(\mathrm{M}=27.37, \mathrm{SD}=3.49)$ and between mature-age males $(\mathrm{M}=$ 31.79 , $\mathrm{SD}=7.43)$ and usual-age females. For surface approach a significant difference occurs between matureage females $(\mathrm{M}=19.09, \mathrm{SD}=3.88)$ and usual-age females $(\mathrm{M}=23.06, \mathrm{SD}=3.49)$.

\subsection{Subscale Analysis-Motivation and Strategy}

The mean score of mature-age female group on the deep motive subscale was the highest out of all four groups, 
with usual-age females scoring the lowest mean score (Figure 5). When examining age-gender cohorts (matureage female, mature-age male, usual-age female, usual-age male), several significant differences were identified between the 4 main dependent subscales (deep motivation, deep strategy, surface motivation, surface strategy). Multivariate analysis showed that there was a significant effect of the age-gender cohort variable (mature-age female, mature-age male ,usual-age female, usual-age male) on the combined dependent variables, $\mathrm{F}(2,514)=$ 5.484, $p=0.00$, partial $\eta_{2}=0.041$.

Analysis of dependent variables individually showed that at a Bonferroni adjusted alpha level of 0.0125 , remained significant, for all groups, including deep motive $\mathrm{F}(2,514)=9.795, p=0.00$, partial $\eta_{2}=0.054$, deep strategy F $(2,514)=10.619, p=0.00$, partial $\eta_{2}=0.058$, surface motive $\mathrm{F}(2,514)=15.395, p=0.00$, partial $\eta 2$ $=0.056$, surface strategy $\mathrm{F}(2,514)=15.395, p=0.00$, partial $\eta_{2}=0.085$.

Post hoc analysis of deep motive revealed that a significant difference occurs between mature-age females ( $\mathrm{M}$ $=16.78, \mathrm{SD}=3.89)$ and usual-age females $(\mathrm{M}=14.35, \mathrm{SD}=3.89)$ and between mature-age males $(\mathrm{M}=16.36$, $\mathrm{SD}=3.90)$ and usual-age females. Post hoc analysis of deep strategy revealed a significant between mature-age females $(M=16.09, S D=4.04)$ and usual-age females $(M=13.37, S D=3.95)$, and between mature-age males $(\mathrm{M}=15.41, \mathrm{SD}=4.03)$ and usual-age females $(\mathrm{M}=13.37, \mathrm{SD}=3.95)$. The surface motive and strategy subscales reveal slightly different patterns (Figure 6), with post hoc analysis revealing that a significant difference occurs between mature-age females $(\mathrm{M}=8.19, \mathrm{SD}=3.02)$ and all other groups, includeing mature-age males

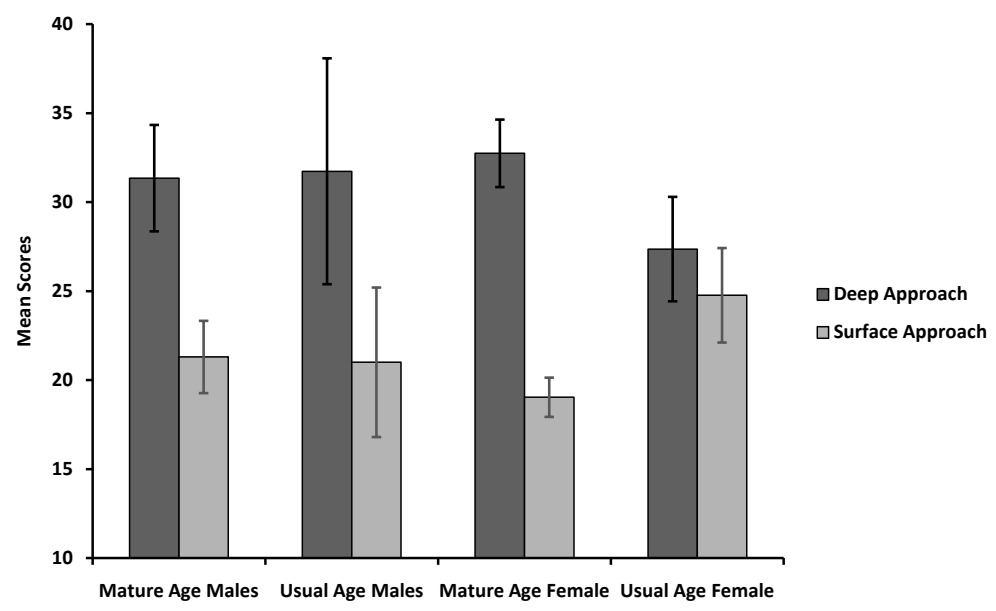

Figure 4. Mean ( \pm 1 standard error) score for deep and surface learning approaches, by gender-age cohort.

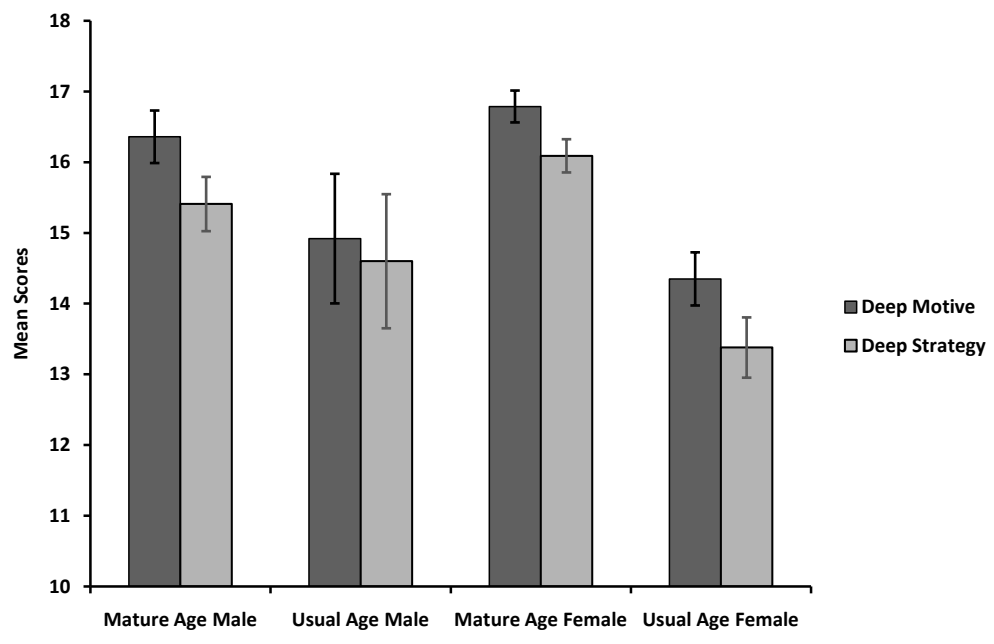

Figure 5. Mean ( \pm 1 standard error) deep and surface learning motive scores, by age-gender group. 


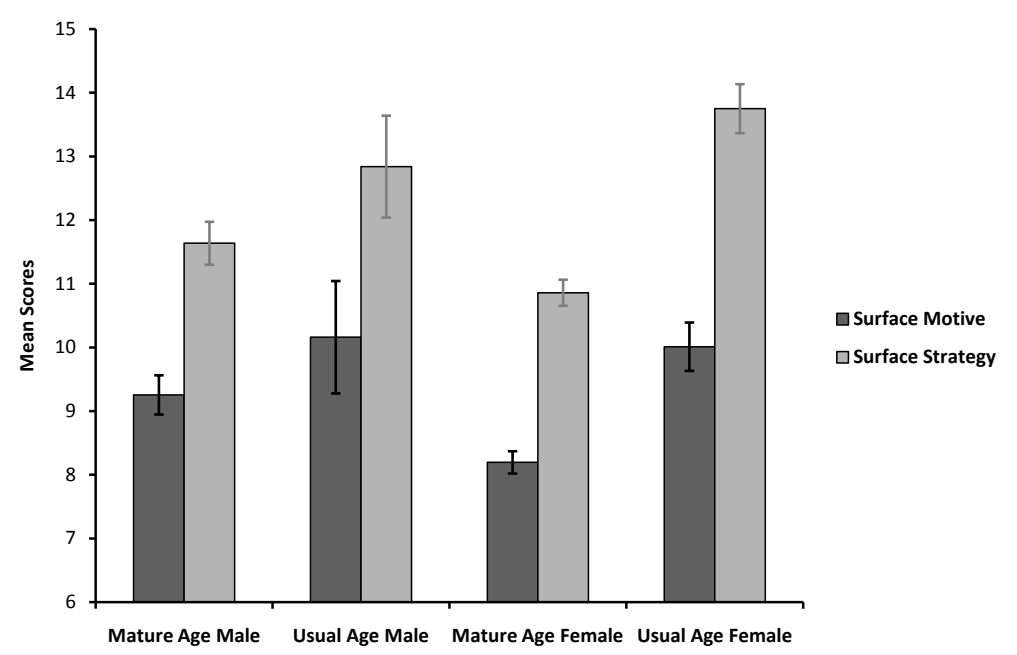

Figure 6. Mean ( \pm 1 standard error) deep and surface learning strategy scores, by age-gender group.

$(\mathrm{M}=9.25, \mathrm{SD}=3.24)$, usual-age males $(\mathrm{M}=10.16, \mathrm{SD}=4.33)$, and usual-age females $(\mathrm{M}=10.01, \mathrm{SD}=3.52)$. In terms of the surface strategy subscale, a significant difference occurs between usual-age females $(M=13.75$, $\mathrm{SD}=3.57)$ and mature-age females $(\mathrm{M}=10.85, \mathrm{SD}=3.53)$, and between usual-age females and mature-age males $(\mathrm{M}=11.63, \mathrm{SD}=3.54)$. Additionally, a significant difference was also identified between usual-age males $(\mathrm{M}=12.84, \mathrm{SD}=3.92)$ and mature-age females.

\section{Discussion}

Given that there is a wide array of potential and demonstrated variables related to both presage factors and the teaching method and environment, it is evident that age is a factor among many others in the approach that a student tends to take towards their learning. This supposition is reinforced by the MANOVA analysis undertaken when considering students in two distinct age groups (mature and usual-age). The broad conclusion from these analyses is that the older a student is, the more likely he or she is to score higher on deep approach, and, conversely, more likely to score lower on surface approach.

These findings are consistent with other studies. Biggs (1987b), for example, found that students aged 18 and over, in a cohort of 2365 students in science, arts and business disciplines at both universities and colleges of advanced education in Australia, adopted a decline in surface approach and an increase in deep and achieving approaches the older they became. Subsequent studies have supported this general conclusion (Baeten et al., 2010; Gow \& Kember, 1990; Richardson, 1994; Sadler-Smith, 1996). Biggs put forward various arguments to explain why age was an important factor. One of his main arguments was that older students "have more to give up", and are therefore more likely to be intrinsically motivated compared to younger students. Further suggestions included that mature-age students read more widely, have a higher level of personal experience, and have the ability to organise their activities better than younger students (Biggs, 1987b). Regan (1996), in her analysis of literature, highlights that mature-age students and, in particular, female mature-age students have many competing demands on their time, demands that impact on the way they approached university studies. Regan (1996) further notes that pressures such as family and work commitments can influence the approach taken. However, directly challenging these difficulties, the results from Regan's study indicate that mature-age students are more inclined towards deep approaches than usual-age students. This supports the results and findings of this current study, as well as the arguments previously presented by Biggs. Given that both the Regan study and the present study are specific to the same university, it may indicate further that this university continues to be an organization that supports mature-age students in higher education studies. The institution has, as Regan (1996) calls it, "a recipe for success" when it comes to supporting mature-age students.

However, putting specific universities aside, other studies support the findings of this study, indicating that mature-age students were more likely to adopt a deep approach compared to younger students (Gow \& Kember, 1990). Studies such as Murray-Harvey (1993) found a strong significant positive correlation between age and deep approach, while also indicating a strong significant negative correlation between age and surface approach. 
Gow \& Kember (1990), in a stepwise multiple linear regression analysis of first-year and last-year university students in Hong Kong, examined the number of years students had left school before entering university. They found that surface motive and surface strategy both decreased with the number of years since a student left school, and that deep motivation increased with age. This supports the idea that life experience is a major factor (Baeten et al., 2010), and that even a few years between leaving school and commencing university has an appreciable effect on the approach a student is likely to take toward university study. Considering that personal experience in organising one's activities tends to be prevalent in mature-age students (Canning, 2010; Regan, 1996), mature-age students are more likely to acquire a greater store of knowledge due to their experience of living and working in the community. The conclusions reached here may, thus, seem unsurprising, given that life experience can be drawn upon as an important resource for learning (Merriam, Caffarella, \& Baumgartner, 2012). Additional to this argument is the level of self-reliance required by mature-age students, which helps them to develop a deep approach (Gow \& Kember, 1990). On the other hand, younger students, with limited life experience, are less likely to have been given the opportunity to develop skills and self-reliance. This suggests that they may be less predisposed to adopting an approach which benefits them academically (Paraeswaran, 1991).

Mature-age students and, in particular mature-age women with children, are often seen to have a deep level of interest in the work they are undertaking, despite having a higher likelihood of greater constraints on their time (Burns, Scott, \& Cooney, 1993; Fulmer \& Jenkins, 1992). This has a potentially significant effect on responses of mature-age students to the demands of university learning. One potential reason advanced for mature students being more likely to develop a deep approach is that they often feel a lack of the necessary skills for tertiary education (Burns et al., 1993; Fulmer \& Jenkins, 1992). Such a perception may generate an appreciable level of anxiety (Richardson, 1994; Whittle, Pell, \& Eaton, 2010; Salisbury \& Karasmanis, 2011), which mature students harness to determine what adjustments are required; they become, therefore, more willing to seek appropriate assistance to help them achieve academically (Power, Robertson, \& Baker, 1987). Conversely, school leavers (those going directly from high school or college to university) often perceive that they are already equipped with the necessary skills because of their immediately previous formal learning experience (Regan, 1996) and they feel they are ready to achieve upon commencement at University. This feeling of confidence contrasts with mature-age students, who tend to feel they lack the skills, and limits younger students from seeking assistance (Regan, 1996). The recent growth, and success, of university preparation courses (Thomas, 2011) reflects the validity of such an argument, demonstrating both the need and the effect of formal assistance in mastering university learning skills, regardless of a student's immature or mature sense of need.

The analyses here into motive and strategy differences between mature-age male/female and usual-age male/female groups may help to examine the effects of maturity more fully. Motivation and life experience have been suggested above as reasons why mature-age students may perform better academically (Diseth \& Kobbeltvedt, 2010). However, the results suggest that this is only partially true. While both mature-age males and females scored a statistically higher score on deep motivation compared to usual-age females, this was not the case for usual-age males, where no significant difference was found. This same pattern also occurred for the deep strategy subscale component. These findings suggest that mature males and females, as well being more motivated, undertook strategies that were more likely to lead to a higher scale score compared to usual-age females but not usual-age males. In terms of surface motivation, once again mature-age women and usual-age women were the critical groups, with mature-age females scoring lower than all other groups and found to be statistically lower than all other groups including mature-age males. When considering surface strategy, usual-age males only showed a significant difference compared to mature-age females who scored lower, while mature-age males and females received a mean score that was considered to be statistically lower than usual-age females. This analysis implies that the general finding that mature-age students performed statistically better on deep and surface approaches was heavily affected by the lowest scores produced by usual-age females as well as the high scores produced by the mature-age females.

From this analysis we can argue that age is an important factor, and that mature-age females do particularly well with regards to the approach they take. Although the relationship between age and scale scores might be considered weak by some, it is important to note that many studies involving the use of the Study Process Questionnaire find similar results. Importantly we need to understand that a wide variety of factors determine the approach we take to our learning. Biggs (1987b) puts the complex nature of learning into context by specifying that correlations between age and SPQ scores do not, in themselves, fully capture all the complexities of student learning. In this regard, other factors that could be investigated would logically include cognitive factors in 
learning outcomes such as brain development (Knudsen, 2004), student involvement as an element in the learning process (Astin, 1984; Johnson, 2015), demographic factors relating to family life and societal factors (Biggs, 1987b; Kovacic, 2010), or whether the students' parents undertook higher education (Biggs, 1987b; Vuong, Brown-Welty, \& Tracz, 2010). Given this complex array of potential influences on a student's tendency towards any particular approach to learning, it is reasonable to not expect an unambiguously significant indicator of the relationship between age and scale score. However, this study, based on a moderately large, wide age-range, and multi-disciplinary student cohort, mirrors other studies, and supports a growing argument that there is a consistent and positive relationship between age and the deep approach scale score, and consistently negative relationship between age and surface approach scale scores. Student age is significant in a student's tendency to adopt a surface or deep learning approach. This study should encourage further investigations regarding the advantages mature-age students have with regards to the learning dimensions covered by the R-SPQ-2F. Additionally, the findings could have implications in terms of contributing to aspects of appropriately targeted, age-specific university preparation programs.

\section{Conclusion}

Age and maturity are determined to be a significant factor that reflects a higher scale score for deep approach and lower score for surface approach. The study demonstrates that mature students are more likely to score higher for the deep approach than younger students. Mature students score a significantly higher mean score on the deep motive subscale, and are, therefore, more likely to be motivated to adopt deep approaches to learning compared to younger students. Mature students also score significantly higher mean scores on the deep strategy subscale, and thus are considered to be more likely to undertake deep strategies to learning compared to younger females. Mature students score a significantly lower mean score on the surface motive subscale, and are therefore, more likely to avoid adopting a surface motivation approach to learning compared to mature males and younger students. Younger female students also score significantly higher mean scores on the surface strategy subscale, and thus are considered to be more likely to undertake surface strategies to learning compared to male cohorts and mature-age females

\section{References}

Astin, A. W. (1984). Student Involvement: A Developmental Theory for Higher Education. Journal of College Student Personnel, 25, 297-308.

Baeten, M., Kyndt, E., Struyven, K., \& Dochy, F. (2010). Using Student-Centred Learning Environments to Stimulate Deep Approaches to Learning: Factors Encouraging or Discouraging Their Effectiveness. Educational Research Review, 5, 243260. http://dx.doi.org/10.1016/j.edurev.2010.06.001

Biggs, J. (1987a). Study Process Questionnaire. Hawthorn: ACER.

Biggs, J. (1987b). Student Approaches to Learning and Studying. Research Monograph, Australian Council for Educational Research, Hawthorn.

Biggs, J. (1999). What the Student Does: Teaching for Enhanced Learning. Higher Education Research \& Development, 18, 57-75. http://dx.doi.org/10.1080/0729436990180105

Biggs, J. (Ed.). (1991). Teaching for Learning: The View from Cognitive Psychology/Edited by John B. Biggs. Hawthorn: Australian Council for Educational Research.

Biggs, J., Kember, D., \& Leung, D. Y. (2001). The Revised Two-Factor Study Process Questionnaire: R-SPQ-2F. The British Journal of Educational Psychology, 71, 133-149. http://dx.doi.org/10.1348/000709901158433

Burns, A., Scott, C., \& Cooney, G. (1993). Higher Education of Single and Married Mothers. Higher Education Research \& Development, 12, 189-206. http://dx.doi.org/10.1080/0729436930120206

Canning, N. (2010). Playing with Heutagogy: Exploring Strategies to Empower Mature Learners in Higher Education. Journal of Further and Higher Education, 34, 59-71. http://dx.doi.org/10.1080/03098770903477102

Case, J., \& Marshall, D. (2004). Between Deep and Surface: Procedural Approaches to Learning in Engineering Education Contexts. Studies in Higher Education, 29, 605-615. http://dx.doi.org/10.1080/0307507042000261571

Clayton, K., Blumberg, F., \& Auld, D. P. (2010). The Relationship between Motivation, Learning Strategies and Choice of Environment Whether Traditional or Including an Online Component. British Journal of Educational Technology, 41, 349-364. http://dx.doi.org/10.1111/j.1467-8535.2009.00993.x

Cofeld, F., Moseley, D., Hall, E., \& Ecclestone, K. (2004). Learning Styles and Pedagogy in Post-16 Learning. A Systematic 
and Critical Review. UK: The Learning and Skills Research Centre (LRSC).

Diseth, Å., Pallesen, S., Brunborg, G. S., \& Larsen, S. (2010). Academic Achievement among First Semester Undergraduate Psychology Students: The Role of Course Experience, Effort, Motives and Learning Strategies. Higher Education, 59, 335-352. http://dx.doi.org/10.1007/s10734-009-9251-8

Diseth, Å., \& Kobbeltvedt, T. (2010). A Mediation Analysis of Achievement Motives, Goals, Learning Strategies, and Academic Achievement. British Journal of Educational Psychology, 80, 671-687. http://dx.doi.org/10.1348/000709910X492432

Diseth, A. (2003). Personality and Approaches to Learning as Predictors of Academic Achievement. European Journal of Personality, 17, 143-155. http://dx.doi.org/10.1002/per.469

Entwistle, N., Tait, H., \& McCune, V. (2000). Patterns of Response to an Approaches to Studying Inventory across Contrasting Groups and Contexts. European Journal of Psychology of Education, 15, 33-48. http://dx.doi.org/10.1007/BF03173165

Freeth, D., \& Reeves, S. (2004). Learning to Work Together: Using the Presage, Process, Product (3P) Model to Highlight Decisions and Possibilities. Journal of Interprofessional Care, 18, 43-56. http://dx.doi.org/10.1080/13561820310001608221

Fulmer, A., \& Jenkins, H. I. (1992). Evaluating a Tertiary Access Program for Mature Age Women. Higher Education Research \& Development, 11, 45-60. http://dx.doi.org/10.1080/0729436920110105

Gow, L., \& Kember, D. (1990). Does Higher Education Promote Independent Learning? Higher Education, 19, $307-322$. http://dx.doi.org/10.1007/BF00133895

Gremli, J. (2003). Impact of Learning-Style Strategies on Music Education. In R. Dunn, \& S. Griggs (Eds.), Synthesis of the Dunnand Dunn Learning Styles Model Research: Who, What, When, Where and So What-The Dunn and Dunn Learning Styles Model and Its Theoretical Cornerstone (pp. 111-114). New York: St John’s University.

Greene, A. (2015). Measuring Cognitive Engagement with Self-Report Scales: Reflections from over 20 Years of Research. Educational Psychologist, 50, 14-30. http://dx.doi.org/10.1080/00461520.2014.989230

Holley, D., \& Oliver, M. (2010). Student Engagement and Blended Learning: Portaits of Risk. Computers \& Education, 54, 693-700. http://dx.doi.org/10.1016/j.compedu.2009.08.035

James, R., Krause, K., \& Jennings, C. (2010). The First Year Experience in Australian Universities: Findings from 1994 to 2009. Melbourne: Centre for the Study of Higher Education, The University of Melbourne, 81 p.

Johnson, G. M. (2015). On-Campus and Fully-Online University Students: Comparing Demographics, Digital Technology Use and Learning Characteristics. Journal of University Teaching \& Learning Practice, 12. http://ro.uow.edu.au/jutlp/vol12/iss1/4

Jiao, X. (2005). Factors Influencing Students’ Approaches to Learning: A Case Study of Postgraduate Students at a New Zealand University. Auckland: Auckland University of Technology.

Kovacic, Z. (2010). Early Prediction of Student Success: Mining Students’ Enrolment Data. Proceedings of the Informing Science and Information Technology Education Joint Conference, Cassino, 19-24 June 2010, 647-665. http://hdl.handle.net/11072/646

Marton, F., \& Säljö, R. (1984). Approaches to Learning. In F. Marton, D. Hounsell, \& N. Entwistle (Eds.), The Experience of Learning (pp. 39-58). Edinburgh: Scottish Academic Press.

Merriam, S. B., Caffarella, R. S., \& Baumgartner, L. M. (2012). Learning in Adulthood: A Comprehensive Guide. Hoboken, NJ: John Wiley \& Sons.

Opfer, V. D., \& Pedder, D. (2011). Conceptualizing Teacher Professional Learning. Review of Educational Research, 81, 376-407. http://dx.doi.org/10.3102/0034654311413609

Paraeswaran, M. (1991). A Comparison of the Academic Success of Mature Age and Traditional Entrants at the Victorian College of Agriculture and Horticulture-Dookie Campus. http://www.aair.org.au/app/webroot/media/pdf/AAIR\%20Fora/Forum1991/Param.pdf

Pyke, S. M., Porter-Dabrowski, C., \& Williamson, N. M. (2014). Impact of Student Approaches to Learning on Both Their Experience and Their Performance in Problem Solving Workshop Classes: A Pilot Study. Proceedings of the Australian Conference on Science and Mathematics Education, Sydney, 29 September-1 October 2014, 75.

Power, C. N., Robertson, F., \& Baker, M. (1987). Success in Higher Education. Commonwealth Tertiary Education, Commission, Canberra: Australian Government Publishing Service.

Regan, J. (1996). First-Year Southern Cross University Students’ Approaches to Learning and Studying: A Replication Study. Master's Thesis, Lismore: Southern Cross University.

Richardson, J. (1994). Mature Students in Higher Education: I. A Literature Survey on Approaches to Studying. Studies in Higher Education, 19, 309-325. http://dx.doi.org/10.1080/03075079412331381900

Ross-Gordon, J. M. (2011). Research on Adult Learners: Supporting the Needs of a Student Population That Is No Longer 
Nontraditional. Peer Review, 13, 26-29.

Salisbury, F., \& Karasmanis, S. (2011). Are They Ready? Exploring Student Information Literacy Skills in the Transition from Secondary to Tertiary Education. Australian Academic \& Research Libraries, 42, 43-58. http://dx.doi.org/10.1080/00048623.2011.10722203

Sherry, M., Thomas, P., \& Chui, W. H. (2010). International Students: A Vulnerable Student Population. Higher Education, 60, 33-46. http://dx.doi.org/10.1007/s10734-009-9284-z

Socha, A., \& Sigler, E. A. (2014). Exploring and "Reconciling” the Factor Structure for the Revised Two-Factor Study Process Questionnaire. Learning and Individual Differences, 31, 43-50. http://dx.doi.org/10.1016/j.lindif.2013.12.010

Thomas, L. (2011). Do Pre-Entry Interventions Such as “Aim Higher” Impact on Student Retention and Success? A Review of the Literature. Higher Education Quarterly, 65, 230-250. http://dx.doi.org/10.1111/j.1468-2273.2010.00481.x

Toohey, S. (1999). Designing Courses for Higher Education. Buckingham: The Society for Research into Higher Education \& Open University Press.

Vanthournount, G., Donche, V., Gijbels, D., \& Petegem, V. (2014). (Dis)similarities in Research on Learning Approaches and Learning Patterns. In D. Gijbels, V. Donche, J. Richardson, \& S. Griggs (Eds.), Learning Patterns in Higher Education: Dimensions and Research Perspectives (pp. 11-32). London and New York: Routledge.

Vuong, M., Brown-Welty, S., \& Tracz, S. (2010). The Effects of Self-Efficacy on Academic Success of First-Generation College Sophomore Students. Journal of College Student Development, 51, 50-64. http://dx.doi.org/10.1353/csd.0.0109

Watkins, D., \& Hattie, J. (1985). A Longitudinal Study of the Approaches to Learning of Australian Tertiary Students. Human Learning: Journal of Practical Research \& Applications, 4, 127-141.

Whittle, S. R., Pell, G., \& Eaton, D. (2010). Recent Changes to Students’ Perceptions of Their Key Skills on Entry to Higher Education. Journal of Further and Higher Education, 34, 557-570. http://dx.doi.org/10.1080/0309877X.2010.512082

Zeegers, P. (2001). Approaches to Learning in Science: A Longitudinal Study. The British Journal of Educational Psychology, 71, 115-132. http://dx.doi.org/10.1348/000709901158424 